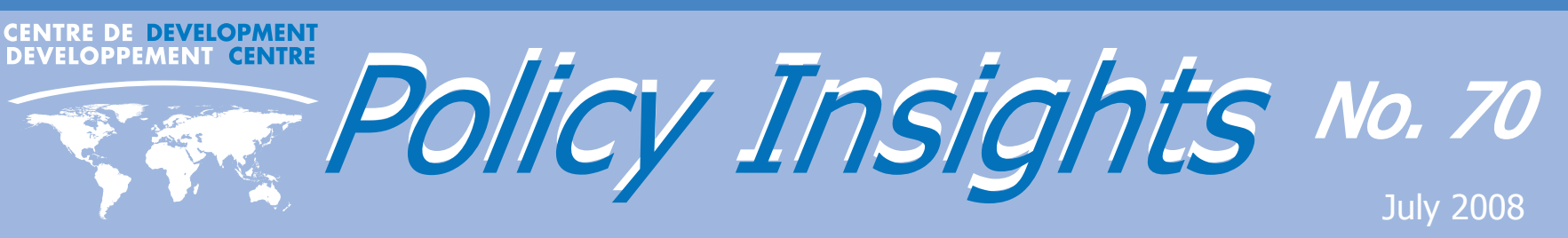

\title{
The Two Faces of Informal Employment in Romania
}

\section{by Denis Drechsler and Theodora Xenogiani, OECD Development Centre}

- Informal employment is a widespread phenomenon in Romania and a key challenge for the country's development

- Policies should target two distinct groups: those who voluntarily opt out of the formal system and those with no alternative

- Transforming people's attitudes towards the state and strengthening their trust in public institutions is key

Many jobs in Romania - as many as half the total - are not subject to labour legislation. Employees often lack access to social protection or employment benefits, and untaxed envelope payments are frequently the rule.

Informality on this scale is a serious problem. It means less tax income for the state and therefore less room to provide infrastructure and public services. The insufficient reach of safety nets to the informal sector renders people vulnerable to economic shock and poverty.

\section{Why Informality?}

Informal employment in Romania cannot be understood without recognising its diverse nature. It is present in many sectors, such as construction, services and agriculture, and takes various shapes and forms, including non-registered firms, false selfemployment and under-declaration of earnings. While some deliberately opt out of the formal system others have no choice but to use informal employment as a livelihood strategy.
Employers choose informality because of high perceived tax and contribution rates, and they get away with it because of insufficient mechanisms to penalise tax evasion. Workers fail to see the link between social security contributions and benefits, and in any case deplore the low quality of public services. Hence they prefer informal employment. Corruption in Romania's public sector is a further disincentive to joining the formal sector (see Figure 1).

Young people, older workers and low-skilled individuals may have no choice but to take informal employment. They simply do not have the necessary requirements to access formal jobs. Their only alternative is poverty.

\section{Wanted: Policies that Work!}

Attempts to reduce informality have had varying degrees of success. The introduction of a flat tax rate in 2005 - following promising results in the Czech Republic - could lower informal employment. The reduction of social contribution rates in 2003 also seems to have been a positive move.

Figure 1. What Explains Informal Employment

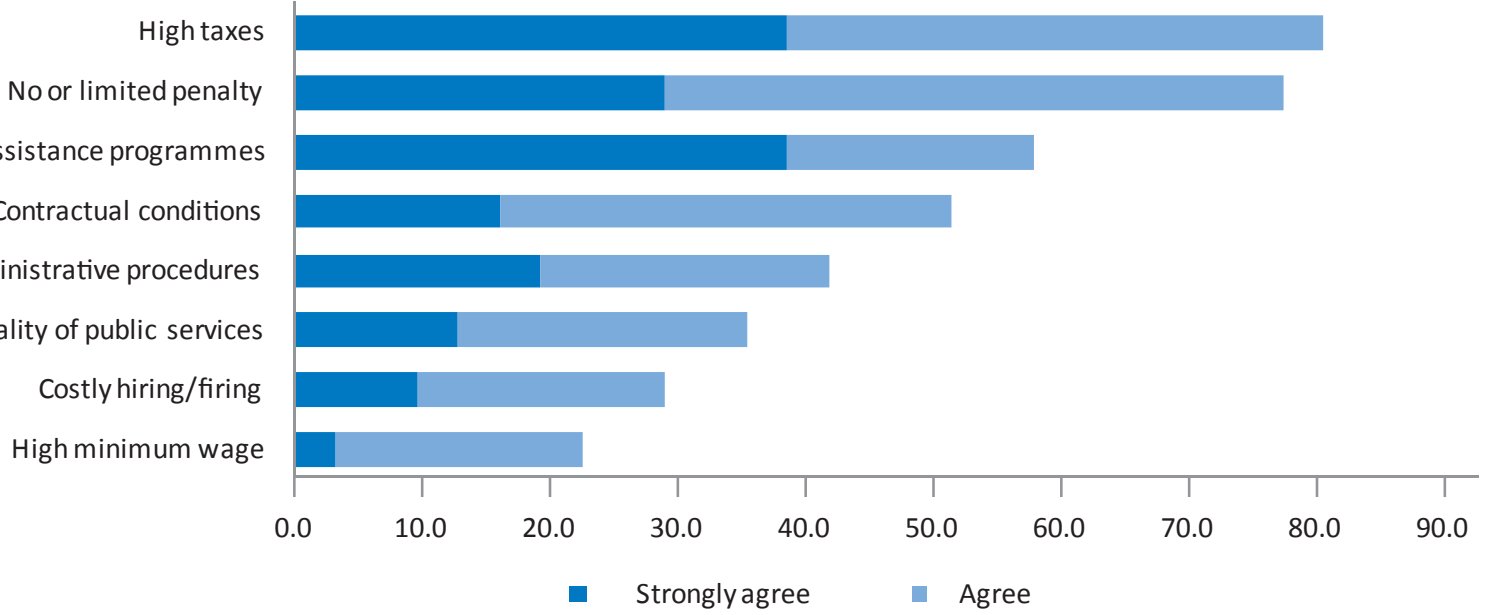

Source: data survey of policy experts (2008). 
Other policies, such as raising minimum wages, seem to have limited the opportunities for formal employment, especially for the most disadvantages groups. Recent social assistance programmes, intended specifically to help people in the informal sector, may have instead given them stronger incentives to remain in informal work. In fact, they may even have driven people out of the formal sector, as similar policies did in Mexico.

\section{Open the Door, but Close the Loopholes}

Reforms in Romania and elsewhere need to reinforce the advantages of the formal sector. At the same time, many reforms fail to adequately address those who have no choice but to work informally. Such people need a different approach from those who voluntarily opt out of the formal sector. A better understanding of the complexity of informal employment and a more nuanced approach to address the specific needs of informal workers are urgently needed.

Active labour market policies, such as training and skilldevelopment programmes, need to re-open the doors to formality. Social assistance programmes can tide over people whose options for entering the labour market are limited. Finding the right balance between guaranteeing social security and providing incentives to join the formal labour market, however, should not be neglected.

Where people have chosen to leave the formal sector, they need to be given incentives to rejoin it. Benefits should be linked to social contribution levels, while administrative procedures such as business and workers' registrations should be simplified. Romania also needs to strengthen enforcement.

\section{A State to Believe In}

Policies can go a long way, but they are no substitute for trust. Informality in Romania is above all an expression of the lack of trust in public institutions, the negative perception of the role of the state and the limited understanding of the benefits derived from social security.

Long term sustainable change requires a transformation of people's attitudes and beliefs. More innovative policies, such as information campaigns on the benefits of formal work and the risks of informality can gradually change people's opinions. While these things won't happen overnight, Romania needs to pave the ground with the right policies and regulations now.

Further Reading:

Jante Parlevliet and Theodora Xenogiani: Report on Informal Employment in Romania, Development Centre Working Paper No. 271, OECD, Paris.

Readers are encouraged to quote or reproduce material from OECD Development Centre Policy Insights for their own publications. In return, the Development Centre requests due acknowledgement and a copy of the publication. Full text of Policy Insights and more information on the Centre and its work are available on its web site: www.oecd.org/dev

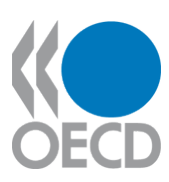

OECD Development Centre 2 , rue André-Pascal,

75775 Paris Cedex 16, France

Tel.: $+33-(0) 145.24 .82 .00$

Fax: +33-(0)144306149

E-mail: dev.contact@oecd.org 